\title{
Role of aldo-keto reductase enzymes in mediating the timing of parturition
}

\section{Michael C. Byrns*}

Department of Health Sciences, Illinois State University, Normal, IL, USA

Edited by:

Yi Jin, University of Pennsy/vania, USA

Reviewed by:

Wei Ni, Michigan State University, USA

Penelope Sheehan, University of Melbourne, Australia

Michel A. Fortier, Laval University

Hospital Center, Canada

*Correspondence:

Michael C. Byrns, Department of

Health Sciences, Illinois State

University, Campus Box 5220,

Normal, IL 61790, USA.

e-mail:mcbyrns@ilstu.edu
A better understanding of the mechanisms underlying parturition would provide an important step toward improving therapies for the prevention of preterm labor. Aldo-keto reductases (AKR) from the 1D, 1C, and 1B subfamilies likely contribute to determining the timing of parturition through metabolism of progesterone and prostaglandins. Placental AKR1D1 (human $5 \beta$ reductase) likely contributes to the maintenance of pregnancy through the formation of $5 \beta$-dihydroprogesterone (DHP). AKR1C1, AKR1C2, and AKR1C3 catalyze the 20-ketosteroid and 3-ketosteroid reduction of progestins. They could therefore eliminate tocolytic progestins at term. Activation of the $\mathrm{F}$ prostanoid receptor by its ligands also plays a critical role in initiation of labor. AKR1C3 and AKR1B1 have prostaglandin (PG) F synthase activities that likely contribute to the initiation of labor. AKR1C3 converts $\mathrm{PGH}_{2}$ to $\mathrm{PGF}_{2 \alpha}$ and $\mathrm{PGD}_{2}$ to $9 \alpha, 11 \beta-\mathrm{PGF}_{2}$. AKR1B1 also reduces $\mathrm{PGH}_{2}$ to $\mathrm{PGF}_{2 \alpha}$, but does not form $9 \alpha, 11 \beta-\mathrm{PGF}_{2}$. Consistent with the potential role for AKR1C3 in the initiation of parturition, indomethacin, which is a potent and isoform selective inhibitor of AKR1C3, has long been used for tocolysis.

Keywords: pregnancy, parturition, placenta, myometrium, prostaglandin metabolism, steroid metabolism, aldoketo reductases

\section{INTRODUCTION}

Preterm birth (prior to 37 weeks gestational age) is the principle cause of neonatal morbidity and mortality in the developed world. The United States has one of the highest rates of preterm births in the developed world, occurring in 12-13\% of pregnancies (Goldenberg et al., 2008). Preterm deliveries account for $75 \%$ of perinatal mortality and surviving preterm infants are at risk for neurological, respiratory, and gastrointestinal complications (Goldenberg et al., 2008; Iams et al., 2008). Treatments such as intravaginal progesterone can be effective at maintaining pregnancies in women at increased risk for preterm labor. Tocolytic therapies to stop active labor do not delay parturition long enough to allow further fetal development, but do provide time for transportation to a hospital with a neonatal intensive care unit (Iams et al., 2008; Mackeen et al., 2011). However, tocolytics have a variety of side effects and there is not enough evidence of benefit to the infant to justify their use (Mackeen et al., 2011).

The mechanisms underlying the initiation of labor are poorly understood, which has limited progress on therapies to maintain pregnancy or stop preterm labor. The lack of a suitable animal model has limited progress toward understanding human parturition (Smith, 2007; Veliça et al., 2009; Hill et al., 2010; Nanjidsuren et al., 2011). The roles of the placenta and other reproductive tissues in parturition, as well as specific steroid and prostaglandin metabolites, differ considerably between mammalian species. Furthermore, the substrate specificities and expression levels of the aldo-keto reductase (AKR) isoforms differ considerably between species. Given the discrepancies in mechanism between species, this review will focus on the AKRs and their substrates and metabolites in human pregnancy.
Progestins play a critical role in human pregnancy, as demonstrated by the efficacy of progesterone in maintaining pregnancy and of the progesterone receptor (PR) antagonist mifepristone in terminating pregnancy and initiating labor (McGill and Shetty, 2007; Iams et al., 2008; Kulier et al., 2011). In other species, a decline in circulating progesterone levels, mediated by distinct pathways, precedes the onset of labor at term (Smith, 2007; Zakar and Hertelendy, 2007). However, serum progesterone levels do not decline during human pregnancies, suggesting that a different mechanism determines the timing of labor. The exact role of progesterone and its metabolites in determining the timing of human labor remains a mystery. Proposed pathways include paracrine regulation through increased myometrial expression of progesterone metabolizing enzymes and/or changes in PR expression. In addition to direct actions of progesterone, actions of its metabolites are likely involved. In particular, $5 \beta$ dihydroprogesterone (5 $\beta$-DHP) inhibits myometrial contractility (Kubli-Garfias et al., 1979; Grazzini et al., 1998; Thornton et al., 1999; Sheehan, 2006). The activities of human AKR1D1 and AKR1Cs suggest they play critical roles in mediating these processes.

Prostaglandins (PG) are also key mediators of parturition. Upregulation of $\mathrm{PGH}_{2}$ synthase 2 occurs late in pregnancy, resulting in an increase in the synthesis of prostaglandins, particularly the $\mathrm{PGF}_{2}$ isomers (Mijovic et al., 1999; Slater et al., 1999; Mitchell et al., 2005; Lee et al., 2008b). Activation of the $\mathrm{F}$ prostanoid (FP) receptor by prostaglandins stimulates cervical ripening and the initiation of labor (Kelly et al., 2003). AKR1B1 and $\mathrm{AKR} 1 \mathrm{C} 3$ are the enzymes that form the $\mathrm{PGF}_{2}$ isomers in humans. 


\section{AKR1D1 IN THE MAINTENANCE OF PREGNANCY}

AKR1D1, human $5 \beta$-reductase, catalyzes the formation of $5 \beta$ androstanes and $5 \beta$-pregnanes and contributes to the formation of bile acids in the liver (Charbonneau and Luu-The, 2001; Chen et al., 2011). Of particular relevance to pregnancy, AKR1D1 catalyzes the conversion of progesterone to $5 \beta$-DHP (Figure 1; Charbonneau and Luu-The, 2001; Chen et al., 2011). 53-DHP may be a key mediator of the pregnancy maintaining effects of progesterone. While levels of progesterone do not decrease during the final week of pregnancy, levels of 5 $\beta$-pregnanes decline starting in week 31 (Hill et al., 2007). This decline appears to be largely the result of decreased $5 \beta$-reduction, although increased downstream metabolism may also occur. Although $5 \beta$-DHP was proposed to bind directly to the oxytocin receptor and antagonize oxytocin binding (Grazzini et al., 1998), others have not been able to replicate this finding (Burger et al., 1999; Astle et al., 2003). 53-DHP could also inhibit contractions through activation of the pregnane X receptor (Mitchell et al., 2005), allosteric modulation of the GABA receptor (Putnam et al., 1991), or through some as yet unknown mechanism. Although the mechanism is uncertain, it is clear that $5 \beta$-DHP limits myometrial contractility; it is significantly more potent than progesterone at inhibiting the contraction of myometrial cells in vitro (Kubli-Garfias et al., 1979; Thornton et al., 1999).

Elevated expression of AKR1D1 likely helps maintain human pregnancy. The placenta appears to be the major site of AKR1D1 expression, although it is also expressed in the myometrium (Sheehan et al., 2005). The decline in 5 3 -DHP levels during labor are accompanied by a significant decline in AKR1D1 mRNA levels. The effect was particularly pronounced in the myometrium, which demonstrated a sevenfold reduction in AKR1D1 levels (Sheehan et al., 2005). Decreased synthesis of relaxatory pregnanes by AKR1D1 may play an important role in the onset of labor.

AKR1D1 exhibits potent substrate inhibition by $\Delta^{4}$-ene steroids due to binding in a non-productive conformation (Di Costanzo et al., 2008; Faucher et al., 2008; Chen et al., 2011),

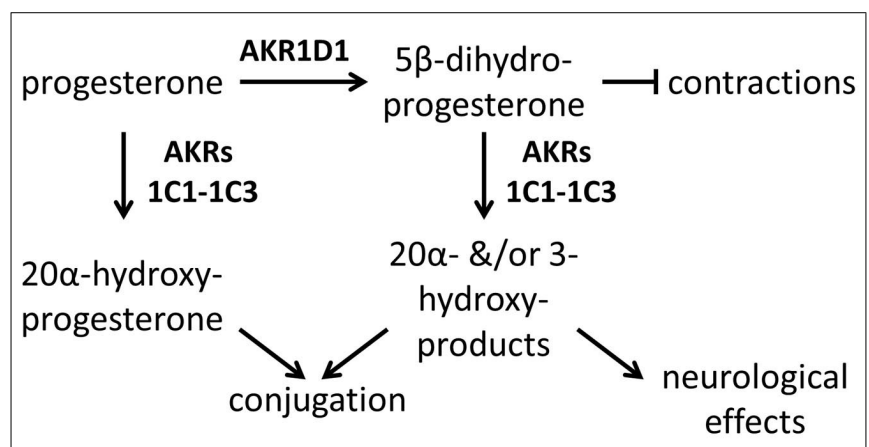

FIGURE 1 | Progesterone metabolism by AKR1D1 and AKR1Cs in pregnancy. AKR1D1 is likely to inhibit myometrial contractions through formation of $5 \beta$-dihydroprogesterone, while AKR1C1, AKR1C2, and AKR1C3 are likely to stimulate contractions through the elimination of progesterone and 5 $\beta$-dihydroprogesterone. AKR1D1 and the AKR1Cs might also contribute to formation of neuroactive progesterone metabolites. The AKR1Cs would have similar activities toward $5 \alpha$-dihydroprogesterone (not shown). suggesting a second mechanism for the regulation of its activity. The presence of other $\Delta^{4}$-ene steroids, particularly 11-deoxycorticosterone and 4-androstene-3,17-dione (Chen et al., 2011), would be anticipated to potently decrease the formation of $5 \beta$ DHP by AKR1D1. 4-Androstenedione levels are slightly elevated during labor, while levels of its aromatase product estrone are very high during labor (Hill et al., 2010). Given the permissive ligand binding pocket of AKR1D1 (Di Costanzo et al., 2008; Faucher et al., 2008), it is likely that steroids that are not substrates, including estrogens, will serve as inhibitors. This inhibition might contribute to the induction of labor by estrogens.

Although it is found in higher concentrations than $5 \beta$-DHP throughout pregnancy, $5 \alpha$-DHP formation does not appear to contribute to the timing of labor. $5 \alpha$-DHP is completely unable to inhibit myometrial contractility in vitro (Kubli-Garfias et al., 1979). Ratios of progesterone to $5 \alpha$-DHP remain constant throughout pregnancy and it appears that expression levels of $5 \alpha-$ reductase enzymes remain elevated throughout pregnancy (Hill et al., 2010). Much of the work that has investigated $5 \alpha$-reduced pregnanes in pregnancy has focused on their neuroendocrine effects, including their anxiolytic and anesthetic effects in the mother, and their important role in protecting the developing nervous system of the neonate (Amin et al., 2006; Hirst et al., 2006;

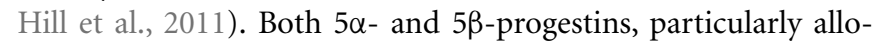
pregnanolone and pregnanolone, act as allosteric modulators of $\mathrm{GABA}_{\mathrm{A}}$ receptors (Reddy, 2010).

\section{KETOSTEROID REDUCTION BY AKR1Cs IN PARTURITION}

Members of the AKR1C subfamily are likely to help initiate labor by catalyzing the formation of inactive progestin metabolites, leading to paracrine suppression of PR signaling (Figure 1). AKR1C1, AKR1C2, and AKR1C3 eliminate progesterone, $5 \alpha$-DHP, and $5 \beta-$ DHP through their 20-ketosteroid reductase activities (Penning et al., 2000; Jin et al., 2011). Furthermore, they possess substantial 3-ketosteroid reductase activities that provide another pathway for the metabolism of $5 \alpha$-DHP and $5 \beta$-DHP (Jin et al., 2011). The $20 \alpha-, 3 \alpha$-, and $3 \beta$-hydroxy-progestin products of AKR1C enzymes have reduced tocolytic activities and are substrates for elimination through glucuronidation or sulfation. The 3-hydroxy products, such as pregnanolone and allopregnanolone, are neuroactive and could contribute to analgesic and anxiolytic effects in the mother and neuroprotection of the fetus (Steckelbroeck et al., 2004; Amin et al., 2006; Hirst et al., 2006; Reddy, 2010; Hill et al., 2011). The stereochemistry for the reduction of 3-ketosteroids varies between AKR1C isoforms and between $5 \alpha$-DHP and $5 \beta$ DHP, while reduction of the ketone at the 20 position exclusively forms the $20 \alpha$-stereoisomer (Jin et al., 2011).

AKR1C1, AKR1C2, and AKR1C3 are expressed in reproductive tissues, including the placenta, myometrium, and cervix (Nishizawa et al., 2000; Andersson et al., 2008; Lee et al., 2008a; Hevir et al., 2011). Placental tissues obtained from pregnancies at term reduce progesterone to $20 \alpha$-hydroxyprogesterone at five times the rate of placentas from the first trimester and there is a further increase in activity with the onset of labor (Milewich et al., 1978; Diaz-Zagoya et al., 1979). It is not known whether expression levels of the AKR1C enzymes correspond to the observed activity. Expression of mRNA encoding AKR1C1 is elevated in 
the myometrium during spontaneous, but not oxytocin induced, labor (Lee et al., 2008a). AKR1C1 has the highest catalytic activity toward 20-ketosteroids, and this enzyme likely plays an important role in the inactivation of myometrial progesterone during spontaneous labor (Penning et al., 2000; Jin et al., 2011). Placental expression of AKR1C3 during pregnancy has primarily been examined in the context of its prostaglandin metabolizing effects and is discussed below. AKR1C2 expression in placenta is the lowest of the three peripheral AKR1C isoforms (Nishizawa et al., 2000) and the contribution of AKR1C2 to parturition may be less critical than AKR1C1 and AKR1C3.

Andersson et al. (2008) used intact tissues from combined hysterectomy and cesarean section to examine the role of AKR mediated 20-ketosteroid reductase activity in cervical ripening. They observed mRNA transcripts corresponding to AKR1C1, AKR1C2, and AKR1C3 in cervix, with AKR1C1 exhibiting the highest expression. Cervical tissue from patients in active labor exhibited considerably faster progesterone 20-ketosteroid reduction relative to patients who were not in labor. However, cervical expression of mRNA for the three AKR1C isoforms did not change with labor onset. The increased reductase activity was proposed to result from decreased expression of type $217 \beta$-hydroxysteroid dehydrogenase, which catalyzes the opposing oxidation reaction (Andersson et al., 2008).

\section{PROSTAGLANDIN SYNTHASE ACTIVITIES OF AKRs}

Prostaglandins also regulate parturition. A critical signal in determining the timing of parturition is the release of calcium due to FP receptor activation. Unlike $\mathrm{PGE}_{2}$, which has receptors that inhibit contractions and others that induce them, $\mathrm{PGF}_{2 \alpha}$ has only labor promoting effects (Brodt-Eppley and Myatt, 1999). The principle phenotype of FP receptor knockout mice is the inability to deliver young at term, which is rescued by the administration of oxytocin (Sugimoto et al., 1997; Kawamata et al., 2008). A selective FP receptor antagonist inhibits myometrial cell contractility in vitro (Friel et al., 2005). Regulation of FP signaling is partially via control of its expression levels and partially through the levels of its $\mathrm{PGF}_{2}$ ligands, which are determined by the expression of $\mathrm{PGH}_{2}$ synthase 2, and AKR1B1 and/or AKR1C3 (Figure 2; Mijovic et al., 1999; Slater et al., 1999; Mitchell et al., 2005; Lee et al., 2008b; Smith et al., 2011; Watanabe, 2011). Transcript for the FP receptor is suppressed

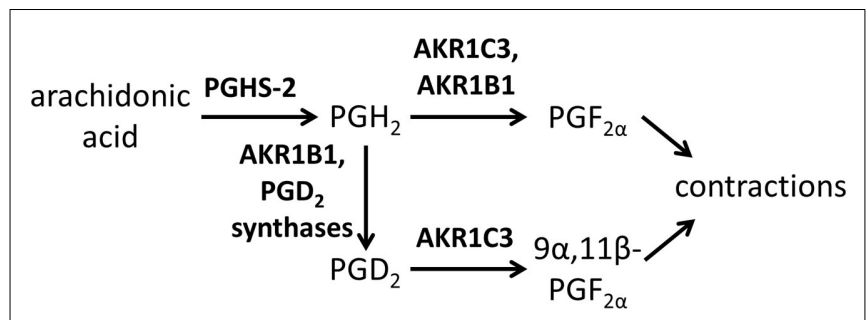

FIGURE 2 | Prostaglandin metabolism by AKR1C3 and AKR1B1 in pregnancy. Both $A K R 1 C 3$ and $A K R 1 B 1$ form $P G F_{2 \alpha}$ from $\mathrm{PGH}_{2}$, while AKR1C3 also forms $9 \alpha, 11 \beta-\mathrm{PGF}_{2}$ and AKR1B1 may also contribute to the formation of $\mathrm{PGD}_{2}$. Both $\mathrm{PGF}_{2}$ isomers will stimulate myometrial contractions through activation of the FP receptor. throughout pregnancy, declining with gestational age until immediately before the initiation of labor, when expression levels spike (Brodt-Eppley and Myatt, 1999; Olson et al., 2003). In sheep corpus luteum and rat myometrium, expression of the FP receptor is upregulated by estradiol administration, while progesterone has a suppressive effect, suggesting that steroids may regulate receptor levels during pregnancy (Hoyer et al., 1999; Dong and Yallampalli, 2000).

The traditional ligand for the FP receptor is $\mathrm{PGF}_{2 \alpha}$, although its stereoisomer $9 \alpha, 11 \beta-\mathrm{PGF}_{2}$ is also a potent ligand (Mitchell et al., 2005). Levels of $\mathrm{PGF}_{2 \alpha}$ in amniotic fluid are low throughout the first 36 weeks of pregnancy before rising during the last few weeks of pregnancy (Lee et al., 2008b). Samples from patients at term indicated a substantial increase in $\mathrm{PGF}_{2 \alpha}$ from no labor $(250 \mathrm{pg} / \mathrm{mL})$ to early labor $(640 \mathrm{pg} / \mathrm{mL})$ and advanced labor $(4300 \mathrm{pg} / \mathrm{mL})$, which was far greater than the increase in $\mathrm{PGE}_{2}$ levels. These measurements were performed with a commercial immunosorbent assay with an antibody against $\mathrm{PGF}_{2 \alpha}$, but cross-reactivity with $9 \alpha, 11 \beta-\mathrm{PGF}_{2}$ was not ruled out. Similar levels of $9 \alpha, 11 \beta-\mathrm{PGF}_{2}(400 \mathrm{pg} / \mathrm{mL})$ were detected in amniotic fluid samples from patients undergoing labor at term using an assay with an antibody that had limited cross-reactivity with $\mathrm{PGD}_{2}$, but not $\mathrm{PGF}_{2 \alpha}$, suggesting that both isomers may play an important role in labor (Mitchell et al., 2005). Elevated levels of $9 \alpha, 11 \beta$ $\mathrm{PGF}_{2}(200 \mathrm{pg} / \mathrm{mL})$ were detected in patients at term who were not undergoing labor, while levels of this isomer were suppressed in patients prior to 36 weeks, including those undergoing preterm labor. The absence of increased $9 \alpha, 11 \beta-\mathrm{PGF}_{2}$ in preterm labor could be the result of low levels of $\mathrm{PGD}_{2}$ synthase or low AKR1C3 activity.

The enzymes responsible for the increased synthesis of $\mathrm{PGF}_{2}$ products at term have not been conclusively identified. However, both of the proposed prostaglandin $\mathrm{F}$ synthases are aldo-keto reductases (Smith et al., 2011; Watanabe, 2011). AKR1C3 forms both $\mathrm{PGF}_{2}$ isoforms. AKR1C3 has substantially higher catalytic activity for the reduction of $\mathrm{PGD}_{2}$ to $9 \alpha, 11 \beta-\mathrm{PGF}_{2}$ relative to its other endogenous substrates, while the conversion of $\mathrm{PGH}_{2}$ to $\mathrm{PGF}_{2 \alpha}$ is also faster than for its steroid substrates (Matsuura et al., 1998; Suzuki-Yamamoto et al., 1999). Involvement of the AKR1B family has only recently been recognized, with the bovine AKR1B5 isoform first shown to synthesize PGF $2 \alpha$ (Madore et al., 2003). In humans, AKR1B1 exhibits a higher catalytic activity for the conversion of $\mathrm{PGH}_{2}$ to $\mathrm{PGF}_{2 \alpha}$ than $\mathrm{AKR} 1 \mathrm{C} 3$, but it is not involved in the formation of $9 \alpha, 11 \beta-\mathrm{PGF}_{2}$ (Kabututu et al., 2009). In addition to synthesizing $\mathrm{PGF}_{2 \alpha}$, a recent report indicates that in the absence of cofactor, AKR1B1 can catalyze the rearrangement of $\mathrm{PGH}_{2}$ to form $\mathrm{PGD}_{2}$; AKR1C3 did not exhibit this activity (Nagata et al., 2011).

AKR1B1 and AKR1C3 are expressed in reproductive tissues during pregnancy and both likely synthesize $\mathrm{PGF}_{2}$ during pregnancy. Both AKR1B1 and AKR1C3 were cloned based on placental DNA libraries (Grundmann et al., 1990; Dufort et al., 1999). Most of the early work on AKR1B1 focused on its role in regulating glucose metabolism, although it has many additional endogenous substrates (Srivastava et al., 2005). Its roles in prostaglandin signaling have only recently been described (Kabututu et al., 2009; Bresson et al., 2011). AKR1C3 also catalyzes the reduction of a 
wide variety of substrates in addition to prostaglandins (Matsuura et al., 1998; Suzuki-Yamamoto et al., 1999; Byrns et al., 2010).

Expression of AKR1B1 and AKR1C3 were recently examined at the mRNA and protein levels in placenta (Breuiller-Fouché et al., 2010). Based on immunohistochemistry, both enzymes were expressed throughout the fetal membranes, but the highest expression was in chorionic trophoblasts and in decidual stromal cells. Western blot and quantitative RT-PCR indicated that AKR1B1 was primarily expressed in the choriodecidua, while AKR1C3 exhibited similar expression levels in both choriodecidua and amnion. Lipopolysaccharide stimulation did not upregulate either protein, suggesting that their expression levels do not contribute to preterm labor induced by intrauterine infection. Changes in placental expression of these enzymes over the course of pregnancy have not been examined.

\section{CONCLUSION}

Further research is needed to understand the contribution of the AKRs to the induction of normal labor. Furthermore, very little is known about the roles of the AKRs in mediating signaling during preterm labor, which may be very different than what occurs at term. Evidence supports a role for declining placental and myometrial AKR1D1 expression in the initiation of labor. Increased paracrine inactivation of progestins by AKR1Cs may also be an important step in parturition. Formation of increased levels of $\mathrm{PGF}_{2}$ isomers stimulates labor, although a major unresolved question is whether changes in the placental expression of AKR1B1 and/or AKR1C3 contribute to this effect. Changes in levels of steroid and prostaglandin products could also result from

\section{REFERENCES}

Amin, Z., Mason, G. F., Cavus, I., Krystal, J. H., Rothman, D. L., and Epperson, C. N. (2006). The interaction of neuroactive steroids and GABA in the development of neuropsychiatric disorders in women. Pharmacol. Biochem. Behav. 84, 635-643.

Andersson, S., Minjarez, D., Yost, N. P., and Word, R. A. (2008). Estrogen and progesterone metabolism in the cervix during pregnancy and parturition. J. Clin. Endocrinol. Metab. 93, 2366-2374.

Astle, S., Khan, R. N., and Thornton, S. (2003). The effects of a progesterone metabolite, $5 \beta$ dihydroprogesterone, on oxytocin receptor binding in human myometrial membranes. BJOG 110 , 589-592.

Bresson, E., Boucher-Kovalik, S., Chapdelaine, P., Madore, E., Harvey, N., Laberge, P. Y., Leboeuf, M., and Fortier, M. A. (2011). The human aldose reductase AKR1B1 qualifies as the primary prostaglandin $\mathrm{F}$ synthase in the endometrium. J. Clin. Endocrinol. Metab. 96, 210-219.
Breuiller-Fouché, M., Leroy, M. J., Dubois, O., Reinaud, P., Chissey, A., Qi, H., Germain, G., Fortier, M. A., and Charpigny, G. (2010). Differential expression of the enzymatic system controlling synthesis, metabolism, and transport of PGF $2_{\alpha}$ in human fetal membranes. Biol. Reprod. 83, 155-162.

Brodt-Eppley, J., and Myatt, L. (1999). Prostaglandin receptors in lower segment myometrium during gestation and labor. Obstet. Gynecol. 93, 89-93.

Burger, K., Fahrenholz, F., and Gimpl, G. (1999). Non-genomic effects of progesterone on the signaling function of $\mathrm{G}$ protein-coupled receptors. FEBS Lett. 464, 25-29.

Byrns, M. C., Duan, L., Lee, S. H., Blair, I. A., and Penning, T. M. (2010). Aldo-keto reductase 1C3 expression in MCF-7 cells reveals roles in steroid hormone and prostaglandin metabolism that may explain its over-expression in breast cancer. J. Steroid Biochem. Mol. Biol. 118, 177-187.

Byrns, M. C., Steckelbroeck, S., and Penning, T. M. (2008). An

changes in other enzymes involved in upstream and downstream metabolism.

Although the contribution of AKR1C3 to labor initiation has not been the subject of much research, its enzymatic activities suggest an important role. Each of its enzymatic activities has the potential to contribute to the initiation of parturition. AKR1C3 can eliminate progesterone and its $5 \alpha$ - and $5 \beta$-reduced products and can synthesize estradiol and both prostaglandin $\mathrm{F}_{2}$ isomers (Byrns et al., 2010; Jin et al., 2011). Furthermore, it is potently inhibited by the tocolytic drug indomethacin (Byrns et al., 2008). It is expressed in several reproductive tissues during pregnancy, although it is not known whether expression levels change, except in the cervix where it does not (Nishizawa et al., 2000; Andersson et al., 2008; Breuiller-Fouché et al., 2010). Further investigation into the role of AKR1C3 in parturition is needed.

It remains to be seen whether targeting AKRs can have benefits in pregnancy. AKR1D1 inhibitors might be useful for inducing cervical ripening or given along with oxytocin for the initiation of labor. Inhibitors of the AKR1B and AKR1C enzymes might have benefits for the maintenance of pregnancy or for tocolysis. However, a number of potential pitfalls make developing pharmacotherapies based on AKRs challenging. The lack of an animal model makes testing these targets challenging. Given that mammals have distinct mechanisms of parturition and AKR substrate specificities, it is not clear that effects in animal models will apply to human pregnancies. Another potential issue is that the AKR1C and AKR1D enzymes contribute to the synthesis of neuroactive steroids, such as allopregnanolone and pregnanolone. Given the neuroprotective effects of these steroids, inhibition of these enzymes in the fetal compartment may be undesirable.

indomethacin analogue, N-(4chlorobenzoyl)-melatonin, is a selective inhibitor of aldo-keto reductase 1C3 (type $23 \alpha-\mathrm{HSD}$, type $517 \beta-\mathrm{HSD}$, and prostaglandin $\mathrm{F}$ synthase), a potential target for the treatment of hormone dependent and hormone independent malignancies. Biochem. Pharmacol. 75, 484-493.

Charbonneau, A., and Luu-The, V. (2001). Genomic organization of a human $5 \beta$-reductase and its pseudogene and substrate selectivity of the expressed enzyme. Biochim. Biophys. Acta 1517, 228-235.

Chen, M., Drury, J. E., and Penning, T. M. (2011). Substrate specificity and inhibitor analyses of human steroid $5 \beta$-reductase (AKR1D1). Steroids 76, 484-490.

Di Costanzo, L., Drury, J. E., Penning, T. M., and Christianson, D. W. (2008). Crystal structure of human liver $\Delta 4$-3-ketosteroid $5 \beta$-reductase (AKR1D1) and implications for substrate binding and catalysis. J. Biol. Chem. 283, 16830-16839.

Diaz-Zagoya, J. C., Wiest, W. G., and Arias, F. (1979). 20 $\alpha$-Hydroxysteroid oxidoreductase activity and $20 \alpha$ dihydroprogesterone concentration in human placenta before and after parturition. Am. J. Obstet. Gynecol. 133, 673-676.

Dong, Y. L., and Yallampalli, C. (2000). Pregnancy and exogenous steroid treatments modulate the expression of relaxant EP2 and contractile FP receptors in the rat uterus. Biol. Reprod. 62, 533-539.

Dufort, I., Rheault, P., Huang, X. F., Soucy, P., and Luu-The, V. (1999). Characteristics of a highly labile human type 5 17betahydroxysteroid dehydrogenase. Endocrinology 140, 568-574.

Faucher, F., Cantin, L., Luu-The, V., Labrie, F., and Breton, R. (2008). Crystal structures of human $\Delta 4-3$ ketosteroid $5 \beta$-reductase (AKR1D1) reveal the presence of an alternative binding site responsible for substrate inhibition. Biochemistry 47, 13537-13546.

Friel, A. M., O’Reilly, M. W., Sexton, D. J., and Morrison, J. J. (2005). Specific PGF2 $\alpha$ receptor (FP) antagonism and human uterine contractility in vitro. BJOG 112, 1034-1042. 
Goldenberg, R. L., Culhane, J. F., Iams, J. D., and Romero, R. (2008). Epidemiology and causes of preterm birth. Lancet 371, 75-84.

Grazzini, E., Guillon, G., Mouillac, B., and Zingg, H. H. (1998). Inhibition of oxytocin receptor function by direct binding of progesterone. Nature 392, 509-512.

Grundmann, U., Bohn, H., Obermeier, R., and Amann, E. (1990). Cloning and prokaryotic expression of a biologically active human placental aldose reductase. DNA Cell Biol. 9, 149-157.

Hevir, N., Vouk, K., Sinkovec, J., Ribič-Pucelj, M., and Rižner, T. L. (2011). Aldo-keto reductases AKR1C1, AKR1C2 and AKR1C3 may enhance progesterone metabolism in ovarian endometriosis. Chem. Biol. Interact. 191, 217-226.

Hill, M., Cibula, D., Havlíková, H., Kancheva, L., Fait, T., Kancheva, R., Pařízek, A., and Stárka, L. (2007). Circulating levels of pregnenolone isomers during the third trimester of human pregnancy. $J$. Steroid Biochem. Mol. Biol. 105, 166-175.

Hill, M., Pařízek, A., Cibula, D., Kancheva, R., Jirásek, J. E., Jirkovská, M., Velíková, M., Kubátová, J., Klímková, M., Pašková, A., Zižka, Z., Kancheva, L., Kazihnitková, H., Zamrazilová, L., and Stárka, L. (2010). Steroid metabolome in fetal and maternal body fluids in human late pregnancy. J. Steroid Biochem. Mol. Biol. 122, 114-132.

Hill, M., Pařízek, A., Kancheva, R., and Jirásek, J. E. (2011). Reduced progesterone metabolites in human late pregnancy. Physiol. Res. 60, 225-241.

Hirst, J. J., Yawno, T., Nguyen, P., and Walker, D. W. (2006). Stress in pregnancy activates neurosteroid production in the fetal brain. Neuroendocrinology 84, 264-274.

Hoyer, P. B., Marion, S. L., Stine, I., Rueda, B. R., Hamernik, D. L., Regan, J. W., and Wise, M. E. (1999). Ovine prostaglandin $\mathrm{F} 2_{\alpha}$ receptor: steroid influence on steady-state levels of luteal mRNA. Endocrine 10, 105-111.

Iams, J. D., Romero, R., Culhane, J. F., and Goldenberg, R. L. (2008). Primary, secondary, and tertiary interventions to reduce the morbidity and mortality of preterm birth. Lancet 371, 164-175.

Jin, Y., Mesaros, A. C., Blair, I. A., and Penning, T. M. (2011). Stereospecific reduction of $5 \beta$-reduced steroids by human ketosteroid reductases of the AKR (aldoketo reductase) superfamily: role of AKR1C1-AKR1C4 in the metabolism of testosterone and progesterone via the $5 \beta$ reductase pathway. Biochem. J. 437, 53-61.

Kabututu, Z., Manin, M., Pointud, J. C., Maruyama, T., Nagata, N., Lambert, S., Lefrançois-Martinez, A. M., Martinez, A., and Urade, Y. (2009). Prostaglandin $\mathrm{F} 2_{\alpha}$ synthase activities of aldo-keto reductase 1B1, 1B3 and 1B7. J. Biochem. 145, 161-168.

Kawamata, M., Yoshida, M., Sugimoto, Y., Kimura, T., Tonomura, Y., Takayanagi, Y., Yanagisawa, T., and Nishimori, K. (2008). Infusion of oxytocin induces successful delivery in prostanoid FP-receptor-deficient mice. Mol. Cell. Endocrinol. 283, 32-37.

Kelly, A. J., Kavanagh, J., and Thomas, J. (2003). Vaginal prostaglandin (PGE2 and PGF2 $2_{\alpha}$ ) for induction of labour at term. Cochrane Database Syst. Rev. 7, CD003101.

Kubli-Garfias, C., Medrano-Conde, L., Beyer, C., and Bondani, A. (1979). In vitro inhibition of rat uterine contractility induced by $5 \alpha$ and $5 \beta$ progestins. Steroids, 34, 609-617.

Kulier, R., Kapp, N., Gülmezoglu, A. M., Hofmeyr, G. J., Cheng, L., and Campana, A. (2011). Medical methods for first trimester abortion. Cochrane Database Syst. Rev. 11, CD002855.

Lee, R. H., Stanczyk, F. Z., Stolz, A., Ji, Q., Yang, G., and Goodwin, T. M. (2008a). AKR1C1 and SRD5A1 messenger RNA expression at term in the human myometrium and chorioamniotic membranes. Am. J. Perinatol. $25,577-582$.

Lee, S. E., Romero, R., Park, I. S. Seong, H. S., Park, C. W., and Yoon, B. H. (2008b). Amniotic fluid prostaglandin concentrations increase before the onset of spontaneous labor at term. J. Matern. Fetal. Neonatal. Med. 21, 89-94.

Mackeen, A. D., Seibel-Seamon, J., Grimes-Dennis, J., Baxter, J. K., and Berghella, V. (2011). Tocolytics for preterm premature rupture of membranes. Cochrane Database Syst. Rev. 5, CD007062.

Madore, E., Harvey, N., Parent, J., Chapdelaine, P., Arosh, J. A., and Fortier, M. A. (2003). An aldose reductase with $20 \alpha$-hydroxysteroid dehydrogenase activity is most likely the enzyme responsible for the production of prostaglandin $\mathrm{F}_{\alpha}$ in the bovine endometrium. J. Biol. Chem. 278, 11205-11212.

Matsuura, K., Shiraishi, H., Hara, A., Sato, K., Deyashiki, Y., Ninomiya,
M., and Sakai, S. (1998). Identification of a principal mRNA species for human 3 $3 \alpha$-hydroxysteroid dehydrogenase isoform (AKR1C3) that exhibits high prostaglandin D2 11-ketoreductase activity. J. Biochem. 124, 940-946.

McGill, J., and Shetty, A. (2007). Mifepristone and misoprostol in the induction of labor at term. Int. J. Gynaecol. Obstet. 96, 80-84.

Mijovic, J. E., Zakar, T., Angelova, J., and Olson, D. M. (1999). Prostaglandin endoperoxide $\mathrm{H}$ synthase mRNA expression in the human amnion and decidua during pregnancy and in the amnion at preterm labour. Mol. Hum. Reprod. 5, 182-187.

Milewich, L., Gant, N. F., Schwarz, B. E., Chen, G. T., and Macdonald, P. C. (1978). Initiation of human parturition. IX. Progesterone metabolism by placentas of early and late human gestation. Obstet. Gynecol. 51, 278-280.

Mitchell, B. F., Mitchell, J. M., Chowdhury, J., Tougas, M., Engelen, S. M., Senff, N., Heijnen, I., Moore, J. T., Goodwin, B., Wong, S., and Davidge, S. T. (2005). Metabolites of progesterone and the pregnane $\mathrm{X}$ receptor: a novel pathway regulating uterine contractility in pregnancy? Am. J. Obstet. Gynecol. 192, 1304-1313.

Nagata, N., Kusakari, Y., Fukunishi, Y., Inoue, T., and Urade, Y. (2011). Catalytic mechanism of the primary human prostaglandin $\mathrm{F} 2 \alpha$ synthase, aldo-keto reductase $1 \mathrm{~B} 1$ prostaglandin D2 synthase activity in the absence of $\operatorname{NADP}(\mathrm{H})$. FEBS J. 278, 1288-1298.

Nanjidsuren, T., Naidansuren, P., Park, C. W., Park, J. J., Yun, S. J., Sim, B. W., Kang, M. H., Lee, S. R., Chang, K. T., and Min, K. S. (2011). Expression and localization of the $20 \alpha$-hydroxysteroid dehydrogenase (HSD) enzyme in the reproductive tissues of the cynomolgus monkey Macaca fascicularis. J. Steroid Biochem. Mol. Biol. 127, 337-344.

Nishizawa, M., Nakajima, T., Yasuda, K., Kanzaki, H., Sasaguri, Y., Watanabe, K., and Ito, S. (2000). Close kinship of human $20 \alpha$-hydroxysteroid dehydrogenase gene with three aldoketo reductase genes. Genes Cells 5 , 111-125.

Olson, D. M., Zaragoza, D. B., Shallow, M. C., Cook, J. L., Mitchell, B. F., Grigsby, P., and Hirst, J. (2003). Myometrial activation and preterm labour: evidence supporting a role for the prostaglandin $\mathrm{F}$ receptora review. Placenta 24(Suppl. A), S47-S54.
Penning, T. M., Burczynski, M. E., Jez, J. M., Hung, C. F., Lin, H. K., Ma, H., Moore, M., Palackal, N., and Ratnam, K. (2000). Human $3 \alpha-$ hydroxysteroid dehydrogenase isoforms (AKR1C1-AKR1C4) of the aldo-keto reductase superfamily: functional plasticity and tissue distribution reveals roles in the inactivation and formation of male and female sex hormones. Biochem. J. 351(Pt 1), 67-77.

Putnam, C. D., Brann, D. W., Kolbeck, R. C., and Mahesh, V. B. (1991). Inhibition of uterine contractility by progesterone and progesterone metabolites: mediation by progesterone and gamma amino butyric acidA receptor systems. Biol. Reprod. 45, 266-272.

Reddy, D. S. (2010). Neurosteroids: endogenous role in the human brain and therapeutic potentials. Prog. Brain Res. 186, 113-137.

Sheehan, P. M. (2006). A possible role for progesterone metabolites in human parturition. Aust. N. Z. J. Obstet. Gynaecol. 46, 159-163.

Sheehan, P. M., Rice, G. E., Moses, E. K., and Brennecke, S. P. (2005). $5 \beta$-dihydroprogesterone and steroid $5 \beta$-reductase decrease in association with human parturition at term. Mol. Hum. Reprod. 11, 495-501.

Slater, D., Dennes, W., Sawdy, R., Allport, V., and Bennett, P. (1999). Expression of cyclo-oxygenase types-1 and -2 in human fetal membranes throughout pregnancy. $J$. Mol. Endocrinol. 22, 125-130.

Smith, R. (2007). Parturition. N. Engl. J. Med. 356, 271-283.

Smith, W. L., Urade, Y., and Jakobsson, P. J. (2011). Enzymes of the cyclooxygenase pathways of prostanoid biosynthesis. Chem. Rev. 111, 5821-5865.

Srivastava, S. K., Ramana, K. V., and Bhatnagar, A. (2005). Role of aldose reductase and oxidative damage in diabetes and the consequent potential for therapeutic options. Endocr. Rev. 26, 380-392.

Steckelbroeck, S., Jin, Y., Gopishetty, S., Oyesanmi, B., and Penning, T. M. (2004). Human cytosolic $3 \alpha$-hydroxysteroid dehydrogenases of the aldo-keto reductase superfamily display significant 33-hydroxysteroid dehydrogenase activity: implications for steroid hormone metabolism and action. J. Biol. Chem. 279, 10784-10795.

Sugimoto, Y., Yamasaki, A., Segi, E., Tsuboi, K., Aze, Y., Nishimura, T., Oida, H., Yoshida, N., Tanaka, 
T., Katsuyama, M., Hasumoto, K., Murata, T., Hirata, M., Ushikubi, F., Negishi, M., Ichikawa, A., and Narumiya, S. (1997). Failure of parturition in mice lacking the prostaglandin F receptor. Science 277, 681-683.

Suzuki-Yamamoto, T., Nishizawa, M., Fukui, M., Okuda-Ashitaka, E., Nakajima, T., Ito, S., and Watanabe, K. (1999). cDNA cloning, expression and characterization of human prostaglandin F synthase. FEBS Lett. 462, 335-340.

Thornton, S., Terzidou, V., Clark, A., and Blanks, A. (1999). Progesterone metabolite and spontaneous myometrial contractions in vitro. Lancet 353, 1327-1329.

Veliça, P., Davies, N. J., Rocha, P. P., Schrewe, H., Ride, J. P., and Bunce, C. M. (2009). Lack of functional and expression homology between human and mouse aldoketo reductase $1 \mathrm{C}$ enzymes: implications for modelling human cancers. Mol. Cancer 8, 121.

Watanabe, K. (2011). Recent reports about enzymes related to the synthesis of prostaglandin (PG) $\mathrm{F}_{2}\left(\mathrm{PGF} 2_{\alpha}\right.$ and $\left.9 \alpha, 11 \beta-\mathrm{PGF}_{2}\right)$. J. Biochem. 150, 593-596.
Zakar, T., and Hertelendy, F. (2007). Progesterone withdrawal: key to parturition. Am. J. Obstet. Gynecol. 196, 289-296.

Conflict of Interest Statement: The author declares that the research was conducted in the absence of any commercial or financial relationships that could be construed as a potential conflict of interest.

Received: 29 November 2011; paper pending published: 07 December 2011; accepted: 20 December 2011; published online: 09 January 2012.
Citation: Byrns MC (2012) Role of aldoketo reductase enzymes in mediating the timing of parturition. Front. Pharmacol. 2:92. doi: 10.3389/fphar.2011.00092

This article was submitted to Frontiers in Experimental Pharmacology and Drug Discovery, a specialty of Frontiers in Pharmacology.

Copyright (C) 2012 Byrns. This is an open-access article distributed under the terms of the Creative Commons Attribution Non Commercial License, which permits non-commercial use, distribution, and reproduction in other forums, provided the original authors and source are credited. 